\title{
Low-dose thioperamide injected into the cerebellar vermis of mice immediately after exposure to the elevated plus-maze impairs their avoidance behavior on re-exposure to the apparatus
}

\author{
J. Costa Neto, K.R. Serafim, A.C.L. Gianlorenço and R. Mattioli \\ Laboratório de Neurociências, Departamento de Fisioterapia, Centro de Ciências Biológicas e da Saúde, \\ Universidade Federal de São Carlos, São Carlos, SP, Brasil
}

\begin{abstract}
The present study investigated the effect of thioperamide (THIO), an $\mathrm{H}_{3}$ histaminergic receptor antagonist, microinjected into the cerebellar vermis on emotional memory consolidation in male Swiss albino mice re-exposed to the elevated plus-maze (EPM). We implanted a guide cannula into the cerebellar vermis using stereotactic surgery. On the third day after surgery, we performed behavioral tests for two consecutive days. On the first day (exposure), the mice ( $n=10 / g r o u p)$ were exposed to the EPM and received THIO $(0.06,0.3$, or $1.5 \mathrm{ng} / 0.1 \mu \mathrm{L})$ immediately after the end of the session. Twenty-four hours later, the mice were re-exposed to the EPM under the same experimental conditions, but without drug injection. A reduction in the exploration of the open arms upon re-exposure to the EPM (percentage of number of entries and time spent in open arms) compared with the initial exposure was used as an indicator of learning and memory. One-way analysis of variance (ANOVA) followed by the Duncan post hoc test was used to analyze the data. Upon re-exposure, exploratory activity in the open arms was reduced in the control group, and with the two highest THIO doses: 0.3 and $1.5 \mathrm{ng} / 0.1 \mu \mathrm{L}$. No reduction was seen with the lowest THIO dose $(0.06 \mathrm{ng} / 0.1 \mu \mathrm{L})$, indicating inhibition of the consolidation of emotional memory. None of the doses interfered with the animals' locomotor activity. We conclude that THIO at the lowest dose $(0.06 \mathrm{ng} / 0.1 \mu \mathrm{L})$ microinjected into the cerebellum impaired emotional memory consolidation in mice.
\end{abstract}

Key words: Histaminergic system; Cerebellum; $\mathrm{H}_{3}$; Emotional memory; Memory consolidation; Elevated plus-maze

\section{Introduction}

Histamine is a biogenic amine, which acts as an important neurotransmitter in the central nervous system (1). It is synthesized in the cell bodies of histaminergic neurons in the nucleus tuberomamillaris in the posterior hypothalamus (1). Axonal projections extend from this nucleus, innervating nearly every region throughout the encephalon, including the cerebellum (1). Central histamine, together with its neurons and connections, as well as its four types of receptors $\left(\mathrm{H}_{1}-\mathrm{H}_{4}\right)$, comprise the histaminergic system (2). Significant evidence indicates that this system is related to processes of learning and emotional memory $(3,4)$. Furthermore, an interesting approach to altering the central histamine concentration has been to activate or block the $\mathrm{H}_{3}$ receptor, since this receptor modulates the synthesis and release of histamine (1).

Currently, several groups of researchers have studied $\mathrm{H}_{3}$ histaminergic receptors to better elucidate the role of these receptors in learning and emotional memory. For example, Orsetti et al. (5) reported that histamine $\mathrm{H}_{3}$-receptor antagonist improves memory retention and reverses the cognitive deficit induced by scopolamine in a two-trial place recognition task; while post-training systemic administration of thioperamide (THIO) facilitated memory consolidation in mice (6). Furthermore, preclinical and clinical studies are currently investigating the potential use of the $\mathrm{H}_{3}$ receptor antagonists for the

Correspondence: R. Mattioli, Laboratório de Neurociências, Departamento de Fisioterapia, Centro de Ciências Biológicas e da Saúde, Universidade Federal de São Carlos, Rod. Washington Luis, km 235, 13565-905 São Carlos, SP, Brasil. Fax: +55-16-3361-2081. E-mail: mattioli@ufscar.br 
treatment of cognitive disorders such as Alzheimer's disease $(6,7)$.

There is evidence that $\mathrm{H}_{3}$ receptors have a role in learning and memory processes. In this context, the elevated plus-maze (EPM) is an experimental model that has been developed primarily to evaluate anxiety (8). It has also been used to infer learning and memory processes by including an additional day of testing, and then comparing the animal's behavioral profile during both tests $(4,9)$.

The cerebellum has a role in motor functions, including an important role as a regulator in the motor system; however, several lines of evidence also indicate a role of the cerebellum in cognitive functions (10). Sacchetti et al. (10) showed that vermis inactivation causes amnesic effects after a fear-conditioning task. Furthermore, some studies have demonstrated a relationship between the histaminergic system and the cerebellum. Shen et al. (11) showed that histamine excites the cerebellar interpositus nucleus cells via the histamine $\mathrm{H}_{2}$-receptor mechanism. Studies conducted in our laboratory showed that microinjection of histamine into the cerebellar vermis impairs emotional memory consolidation in mice (9). Although, these studies have indicated that histaminergic receptors could have a modulatory effect on memory processes, there have been no reports about the effects of histamine mediated by $\mathrm{H}_{3}$ receptors present in the cerebellum on the consolidation of memory using repeated testing in an EPM.

Therefore, the present study evaluated the effect of THIO, an $\mathrm{H}_{3}$ histaminergic receptor antagonist, microinjected into the cerebellar vermis on emotional memory consolidation in mice exposed to EPM testing.

\section{Material and Methods}

\section{Animals}

A total of 40 male Swiss albino mice, weighing $25-35 \mathrm{~g}$ and aged 4-5 weeks, were used in this study. The animals were obtained from the Central Animal Facility of the Universidade Federal de São Carlos. The mice were housed in groups of 4 mice per cage $(31 \times 20 \times 13 \mathrm{~cm})$, maintained under controlled temperature $\left(21 \pm 1^{\circ} \mathrm{C}\right)$, humidity $(50 \pm 5 \%)$ and lighting (100 lux), with a 12-h light-dark period (lights on at 7:00 am). The animals had free access to food and drinking water, except during the brief testing periods. All mice were experimentally naive, and the experimental sessions were performed during the light phase of the cycle (7:00 am to $3: 00 \mathrm{pm})$.

\section{Ethics}

The experimental procedures used in this study were performed in accordance with the procedures of the Brazilian Neuroscience and Behavior Society (SBNeC), which are based on the U.S. National Institutes of Health Guide for Care and Use of Laboratory Animals, and were approved by the Animal Ethics Commission of the Universidade Federal de São Carlos (CEPEA-UFSCar).

\section{Cannula guide implantation}

The animals were anesthetized intraperitoneally (ip) with $100 \mathrm{mg} / \mathrm{kg}$ ketamine and $10 \mathrm{mg} / \mathrm{kg}$ xylazine, and positioned in a stereotactic frame for implantation of a single stainless steel guide cannula ( 25 gauge, $7 \mathrm{~mm}$ ) into the cerebellar vermis. The stereotaxic coordinates were determined according to the Franklin and Paxinos atlas (12): $6.5 \mathrm{~mm}$ posterior to bregma, $0.0 \mathrm{~mm}$ lateral to midline, and $2.0 \mathrm{~mm}$ ventral to the skull surface. The guide cannula was fixed to the skull with screws and acrylic dental cement. A dummy cannula (33-gauge stainless steel wire) was inserted into the guide cannula to reduce the incidence of occlusion and was removed prior to the microinjection. During the 3 days immediately after surgery, the animals were treated with paracetamol which was added to the drinking water at a ratio of $0.2 \mathrm{~mL}$ paracetamol to $250 \mathrm{~mL}$ water (final concentration: $0.16 \mathrm{mg} / \mathrm{mL})$.

\section{Drugs and microinjection}

Thioperamide maleate salt ( $\mathrm{THIO}$; an $\mathrm{H}_{3}$-receptor antagonist; Sigma, USA) was dissolved in $0.9 \%$ saline at three different concentrations: $0.06,0.3$, and $1.5 \mathrm{ng} /$ $0.1 \mu \mathrm{L}$. The doses administered were based on a previous study (5) and on pilot work in our laboratory. The control group received $0.9 \%$ saline. All three doses of $\mathrm{THIO}$, as well as saline, were labeled using a coding system, following a blind study protocol. Each experimental group $(n=10)$ received one of the four treatments.

The substances were microinjected into the cerebellar vermis using a microinjection unit (33 gauge), which extended $1.0 \mathrm{~mm}$ beyond the end of the guide cannula. The needle was connected to a Hamilton microsyringe $(5.0 \mu \mathrm{L})$ through a polyethylene tube (PE-10), and administration of the four different solutions was controlled using an infusion pump (BI Insight 2000; Equipamentos Científicos Ltda., Brazil) that was programmed to administer $0.1 \mu \mathrm{L}$ solution over $60 \mathrm{~s}$. During the microinjections, the animals were gently restrained while the needle was inserted and solution was infused. To avoid reflux, the animals were kept restrained, maintaining the injection needle in situ for an additional $60 \mathrm{~s}$ after the infusion. Monitoring the movement of a small air bubble into the PE-10 tubing confirmed the success of the microinjections.

\section{Apparatus}

The EPM consisted of two open arms $(30 \times 5 \times 0.25 \mathrm{~cm})$ and two enclosed arms $(30 \times 5 \times 15 \mathrm{~cm})$ connected to a common central platform $(5 \times 5 \mathrm{~cm})$. The apparatus was made of acrylic and raised to a height of $38.5 \mathrm{~cm}$ above ground level. All of the tests were performed under moderate illumination (77 lux), as measured on the central 
platform of the EPM. The apparatus was isolated from the rest of the room using an opaque black curtain.

\section{Experimental procedure}

Behavioral testing began 3 days after surgery. The tests were performed on two consecutive days. On the first day, the animals were exposed to the EPM (Trial 1), and this was followed by a second trial $24 \mathrm{~h}$ later. The animals were transported to the experimental room and allowed to rest for at least $1 \mathrm{~h}$ in order to adapt to the experimental environment. After that, each animal was carefully placed on the central platform of the EPM, facing one of the open arms, and had $300 \mathrm{~s}$ to explore the maze. Immediately after the exposure, the animals received a microinjection of the substance corresponding to their experimental group. After $24 \mathrm{~h}$, the animals were subjected to the same experimental procedure, but in the absence of the microinjection (Trial 2). The maze was thoroughly cleaned with $5 \%$ alcohol and dry cloths between animals.

\section{Behavioral analysis}

All sessions were recorded using a digital camera that was connected to a computer in an adjacent room. The images were analyzed by a trained observer using the XPLO-RAT ethological analysis software developed at the Laboratory of Exploratory Behavior, USP, Ribeirão Preto, Brazil. The conventional measurements recorded were the number of enclosed-arm entries (EAE; arm entry = all four paws into an arm), the percentage of open-arm entries $[\% O A E=($ open/total $) \times 100]$ and the percentage of time spent (\%OAT) in the open arms of the maze [(time open/300 s) $\times 100$ ]. An increase in open-arm avoidance with repeated maze exposure has been observed in several studies and has been used as a measure of learning and memory evaluated by Trial 1/Trial 2 (test/ retest) protocols $(4,9)$.

\section{Histology}

At the end of the experiment, the animals were deeply anesthetized by ip injection of $100 \mathrm{mg} / \mathrm{kg}$ ketamine hydrochloride plus $10 \mathrm{mg} / \mathrm{kg}$ xylazine, and received $0.1 \mu \mathrm{L} 1 \%$ methylene blue (intracerebellar) following the microinjection procedure described above. The brain was removed, and the injection site was examined histologically according to the Franklin and Paxinos atlas (12). Data obtained from mice with incorrect implantation $(n=7)$ of the guide cannula were excluded from the analysis. Histology confirmed that a total of 40 mice had accurate cannula placements in the cerebellar dorsal vermis (Figure 1).

\section{Statistical analysis}

All results were initially subjected to the Levene test for homogeneity of variance. The data were analyzed using ANOVA. The differences were confirmed using the Duncan test. $A$ value of $P<0.01$ was considered to be significant.

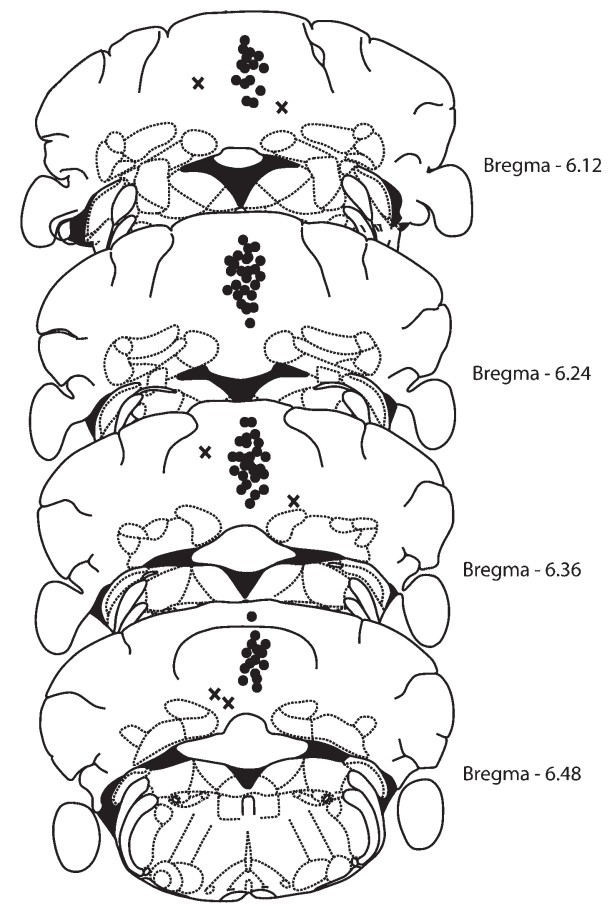

Figure 1. Schematic representation adapted from Franklin and Paxinos (12) of sites of microinfusion into the cerebellum of mice. The points represent correct site injections (the number of points is smaller than the total number of mice because of overlaps).

\section{Results}

One-way ANOVA showed no significant differences among the groups in Trial 1 for all the measures analyzed. Therefore, the data were pooled because the animals had received no pharmacological treatment at that point.

The effects of THIO microinfusion into the cerebellar vermis of mice re-exposed to the EPM on \%OAE, \%OAT and EAE are shown in Figure 2.

ANOVA indicated that there was a difference in \%OAE $(F=14.617, P<0.001)$ when comparing the exposure (Trial 1) results with those for the re-exposure. The Duncan post hoc test showed a reduction in the \%OAE for the saline group, 0.3 and $1.5 \mathrm{ng} / 0.1 \mu \mathrm{L}$ THIO groups compared with the pooled Trial 1 data $(P<0.001)$. This reduction in \%OAE, however, was not observed in the $0.06 \mathrm{ng} / 0.1 \mu \mathrm{L}$ THIO group $(\mathrm{P}>0.001)$. The statistical analysis also demonstrated an increase in \%OAE for the lowest dose $\mathrm{THIO}$ group compared with the saline group on re-exposure $(\mathrm{P}<0.001)$.

Similar results were found for the \%OAT $(F=25.58$, $\mathrm{P}<0.001$ ) when comparing the exposure (Trial 1$)$ results with those for the re-exposure. The post hoc test showed a reduction in the \%OAT for the saline, 0.3 and $1.5 \mathrm{ng} /$ $0.1 \mu \mathrm{L}$ THIO groups compared with the pooled Trial 1 data $(P<0.001)$. No differences were observed for the 

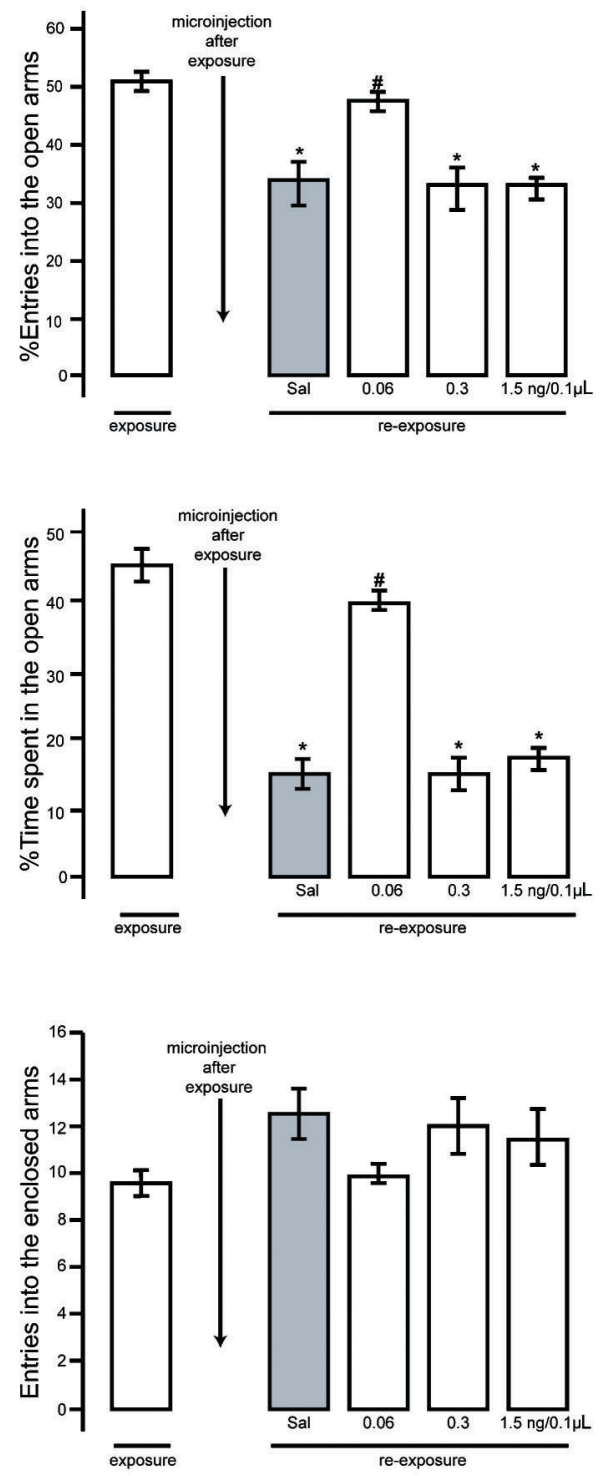

Figure 2. Effect of microinjection of thioperamide (THIO; 0.06, 0.3 and $1.5 \mathrm{ng} / 0.1 \mu \mathrm{L}$ ) and saline (Sal) into the cerebellar vermis on the percent of open-arm entries, percent of time spent in the open arms and the number of enclosed-arm entries at exposure and re-exposure. Data are reported as means $\pm S E .{ }^{*} P<0.001$ re-exposure compared to exposure. ${ }^{\#} \mathrm{P}<0.01, \mathrm{THIO}$ compared to saline at re-exposure (ANOVA followed by the Duncan post hoc test).

$0.06 \mathrm{ng} / 0.1 \mu \mathrm{L}$ THIO group $(\mathrm{P}>0.001)$ compared with the pooled Trial 1 data. On re-exposure, the post hoc test indicated an increase in \%OAT for the lowest dose THIO group compared with the saline group.

None of the doses of THIO interfered with the animals' locomotor activity because there were no differences in $\operatorname{EAE}(\mathrm{F}=2.363$ and $\mathrm{P}>0.001)$.

\section{Discussion}

Emotional memory can be inferred by analyzing the exploratory behavioral profile of animals in the EPM. Our results showed a decrease in exploratory activity in the open arms (\%OAE and \%OAT) for the control group and for the two highest doses of THIO (0.3 and $1.5 \mathrm{ng} / 0.1 \mu \mathrm{L})$. The behaviors exhibited by the animals during the test were possibly due to a conflict between the motivation to explore the maze and the natural tendency to avoid open spaces (13). The inclusion of a retest session is consistent with the assumption that there is a learned component underlying the exploratory behavior during EPM re-exposure (9). After the previous experience on the first test day (exposure), it is expected that on the second day (re-exposure), these animals avoid the risky areas (open arms). However, a reduction in exploratory activity in the open arms was not observed in the group treated with the lowest dose of THIO $(0.06 \mathrm{ng} / 0.1 \mu \mathrm{L})$ into the cerebellar vermis, indicating an impairment of emotional memory consolidation in those mice.

The impairment of learning and memory demonstrated at the lowest dose of THIO tested in the present study was consistent with previous studies performed by our research group. Gianlorenço et al. (14) and Serafim et al. (4) also found inhibitory effects of ip injection of Lhistidine, a histamine precursor, on emotional memory using the same experimental protocol. Another study conducted by Gianlorenço et al. (9) demonstrated that histamine microinjected into the cerebellar vermis of mice impaired memory consolidation. We suggest that altering the concentration of cerebellar histamine via a direct microinjection of THIO into the cerebellar vermis increases endogenous histamine, impairing emotional memory consolidation. Our results, however, differ from those of several studies that showed THIO-facilitated learning and memory consolidation. Bernaerts et al. (15) reported that $\mathrm{THIO}$, an $\mathrm{H}_{3}$ antagonist, enhanced memory consolidation in a dose-dependent manner and reversed amnesia induced by dizocilpine or scopolamine in a onetrial inhibitory avoidance task in mice. However, ip injection of THIO had no effect on spatial learning (16).

In the present study, the lowest dose of THIO (0.06 ng) was sufficient to increase the concentration of cerebellar histamine to impair memory consolidation in mice. The present results may be due to the effect of histamine on one of the well-organized cerebellar projections, indicating that emotional behavior expression in rodents is under the tonic modulatory control of this neurotransmitter. It has been previously proposed that the amygdala and cerebellum are functionally interconnected during aversive learning. A study conducted by Heath et al. (17) showed that vermal electrical stimulation modulates amygdala activity. A study in humans showed that cerebellar lesions are associated with a decrease in the activity of the amygdala as well as of the cingulated gyrus (18). 
Our results also showed that, at the two higher doses of THIO (0.3 and $1.5 \mathrm{ng}$ ), there were no effects on emotional memory consolidation. It has been shown that the $\mathrm{H}_{3}$ receptor functions as a heteroreceptor, regulating the release of other central neurotransmitters, such as acetylcholine and serotonin, which can modulate learning and memory processes. Furthermore, higher doses of THIO can activate the other two histaminergic receptors, $\mathrm{H}_{1}$ and $\mathrm{H}_{2}$. THIO does not have a high level of specificity for the $\mathrm{H}_{3}$ receptor, and there is evidence that the $\mathrm{H}_{1}$ receptor is the predominant histaminergic receptor in the cerebellum (19). Intra-vermal cerebellar administration of chlorpheniramine, an $\mathrm{H}_{1}$-receptor antagonist, prior to histamine infusion, significantly reduced open-arm exploration compared with a group that was microinjected with histamine only, indicating possible involvement of this receptor in histamine-induced memory impairment in mice (20).

Studies conducted on animals have shown that the

\section{References}

1. Haas $H$, Panula $P$. The role of histamine and the tuberomamillary nucleus in the nervous system. Nat Rev Neurosci 2003; 4: 121-130, doi: 10.1038/nrn1034.

2. Leurs R, Smit MJ, Timmerman H. Molecular pharmacological aspects of histamine receptors. Pharmacol Ther 1995; 66: 413-463, doi: 10.1016/0163-7258(95)00006-3.

3. Alvarez EO. The role of histamine on cognition. Behav Brain Res 2009; 199: 183-189, doi: 10.1016/j.bbr.2008.12.010.

4. Serafim KR, Kishi M, Canto-de-Souza A, Mattioli R. L-histidine provokes a state-dependent memory retrieval deficit in mice re-exposed to the elevated plus-maze. Braz $J$ Med Biol Res 2010; 43: 100-106, doi: 10.1590/S0100879X2009007500025.

5. Orsetti M, Ghi P, Di Carlo G. Histamine H(3)-receptor antagonism improves memory retention and reverses the cognitive deficit induced by scopolamine in a two-trial place recognition task. Behav Brain Res 2001; 124: 235-242, doi: 10.1016/S0166-4328(01)00216-9.

6. Charlier Y, Brabant C, Serrano ME, Lamberty Y, Tirelli E. The prototypical histamine $\mathrm{H}$ receptor inverse agonist thioperamide improves multiple aspects of memory processing in an inhibitory avoidance task. Behav Brain Res 2013; 253C: 121-127, doi: 10.1016/j.bbr.2013.07.016.

7. Nathan PJ, Boardley R, Scott N, Berges A, Maruff P, Sivananthan $\mathrm{T}$, et al. The safety, tolerability, pharmacokinetics and cognitive effects of GSK239512, a selective histamine $\mathrm{H}(3)$ receptor antagonist in patients with mild to moderate Alzheimer's disease: a preliminary investigation. Curr Alzheimer Res 2013; 10: 240-251, doi: 10.2174/ 1567205011310030003

8. File SE. The interplay of learning and anxiety in the elevated plus-maze. Behav Brain Res 1993; 58: 199-202, doi: 10.1016/0166-4328(93)90103-W.

9. Gianlorenço AC, Canto-de-Souza A, Mattioli R. Microinjection of histamine into the cerebellar vermis impairs emotional memory consolidation in mice. Brain Res Bull 2011; 86: 134-138, doi: 10.1016/j.brainresbull. cholinergic system plays an important role in learning and memory and the impairment of central cholinergic transmission by pharmacological antagonism is associated with cognitive deficits $(5,6)$. Furthermore, the interaction between histaminergic and cholinergic systems in emotional memory modulation may be an insight toward the development of treatments for Alzheimer's disease (7).

In conclusion, the results indicated that the lowest dose of THIO microinjected into the cerebellar vermis impaired emotional memory consolidation in mice reexposed to the EPM.

\section{Acknowledgments}

We would like to thank Azair Liane Matos do Canto de Souza for providing her laboratory for histological analysis. Research supported by CAPES and CNPq (\#300543/ 2010-7).

\subsubsection{4}

10. Sacchetti B, Baldi E, Lorenzini CA, Bucherelli C. Cerebellar role in fear-conditioning consolidation. Proc Natl Acad Sci U S A 2002; 99: 8406-8411, doi: 10.1073/pnas.112660399.

11. Shen B, Li HZ, Wang JJ. Excitatory effects of histamine on cerebellar interpositus nuclear cells of rats through $\mathrm{H}(2)$ receptors in vitro. Brain Res 2002; 948: 64-71, doi: 10.1016/ S0006-8993(02)02950-5.

12. Franklin KBJ, Paxinos G. The mouse brain: in the stereotaxic coordinates. 2nd edn. San Diego: Academic Press; 2001.

13. Lister RG. The use of a plus-maze to measure anxiety in the mouse. Psychopharmacology 1987; 92: 180-185.

14. Gianlorenço AC, Canto-de-Souza A, Mattioli R. L-histidine induces state-dependent memory deficit in mice mediated by $\mathrm{H}_{1}$ receptor. Prog Neuropsychopharmacol Biol Psychiatry 2011; 35: 91-95, doi: 10.1016/j.pnpbp.2010.09.006.

15. Bernaerts $\mathrm{P}$, Lamberty $\mathrm{Y}$, Tirelli $\mathrm{E}$. Histamine $\mathrm{H} 3$ antagonist thioperamide dose-dependently enhances memory consolidation and reverses amnesia induced by dizocilpine or scopolamine in a one-trial inhibitory avoidance task in mice. Behav Brain Res 2004; 154: 211-219, doi: 10.1016/ j.bbr.2004.02.017.

16. Komater VA, Buckley MJ, Browman KE, Pan JB, Hancock $A A$, Decker MW, et al. Effects of histamine $\mathrm{H} 3$ receptor antagonists in two models of spatial learning. Behav Brain Res 2005; 159: 295-300, doi: 10.1016/j.bbr.2004.11.008.

17. Heath RG, Dempesy CW, Fontana CJ, Myers WA. Cerebellar stimulation: effects on septal region, hippocampus, and amygdala of cats and rats. Biol Psychiatry 1978; 13: 501-529.

18. Turner BM, Paradiso S, Marvel CL, Pierson R, Boles Ponto LL, Hichwa RD, et al. The cerebellum and emotional experience. Neuropsychologia 2007; 45: 1331-1341, doi: 10.1016/j.neuropsychologia.2006.09.023.

19. Kohler CA, da Silva WC, Benetti F, Bonini JS. Histaminergic mechanisms for modulation of memory systems. Neural 
Plast 2011; 2011: 328602, doi: 10.1155/2011/328602.

20. Gianlorenço AC, Serafim KR, Canto-de-Souza A, Mattioli R.

Emotional memory consolidation impairment induced by histamine is mediated by $\mathrm{H} 1$ but not $\mathrm{H} 2$ receptors. Brain Res Bull 2012; 89: 197-202, doi: 10.1016/j.brainresbull. 2012.09.003. 